\title{
Efficient semitransparent small-molecule organic solar cells
}

\author{
Jan Meiss, ${ }^{1, a)}$ Karl Leo, ${ }^{1}$ Moritz K. Riede, ${ }^{1}$ Christian Uhrich, ${ }^{2, b)}$ Wolf-Michael Gnehr, ${ }^{2}$ \\ Stefan Sonntag, ${ }^{2}$ and Martin Pfeiffer ${ }^{2}$ \\ ${ }^{1}$ Institut für Angewandte Photophysik, Technische Universität Dresden, D-01062 Dresden, Germany \\ ${ }^{2}$ heliatek GmbH, Liebigstraße 26, D-01187 Dresden, Germany
}

(Received 23 September 2009; accepted 5 November 2009; published online 25 November 2009)

\begin{abstract}
We present semitransparent small-molecule organic solar cells (OSC) deposited by thermal evaporation onto indium tin oxide (ITO)-coated glass substrates. The devices employ ITO-free ultrathin metal layers as top electrodes, containing $1 \mathrm{~nm}$ metal surfactant interlayer for improved morphology. Using a bulk heterojunction of zinc phthalocyanine and $\mathrm{C}_{60}$, sandwiched in between doped dedicated transport layers for efficient charge carrier extraction, power conversion efficiencies comparable to conventional OSC with an intransparent thick back electrode and similar device layout are achieved: the semitransparent OSC yield power conversion efficiencies well above $2 \%$ with external quantum efficiencies above $30 \%-40 \%$. Organic light incoupling layers improve the transmission to up to 50\% in the visible part of the optical spectrum. (C) 2009 American Institute of Physics. [doi:10.1063/1.3268784]
\end{abstract}

Organic solar cells (OSC) have attracted considerable interest as a potential cost-efficient alternative to current inorganic solar cells. Since the major breakthrough with a copper phthalocyanine/perylene derivative heterojunction by Tang, ${ }^{1}$ having a $0.95 \%$ power conversion efficiency (PCE) under AM2 simulated sunlight, advanced materials and concepts have resulted in certified efficiencies of over $6 \%$ for a $2 \mathrm{~cm}^{2}$ oligmer device 2,3 and $6.77 \%$ for a $0.047 \mathrm{~cm}^{2}$ polymer device. $^{4}$

Among the many attractive features of OSC is the possibility to realize homogeneous semitransparent devices. Such devices are of interest for sun shading and power window applications. ${ }^{5,6}$ They are realized by employing electrodes on both sides of the OSC material stack with transmission in the visible part of the optical spectrum. Due to limitations of the top electrode or device architecture, PCEs have so far been below $\eta<0.6 \%$ for semitransparent smallmolecule OSC, ${ }^{5,6}$ which represents a huge reduction compared to intransparent cells and is well below what is needed for a meaningful application.

In this letter, we describe the fabrication of optimized semitransparent small-molecule OSC. A high photocurrent is ensured by utilizing a bulk heterojunction $(\mathrm{BHJ}){ }^{7}$ sandwiched by doped organic layers for optimized energy level alignment. ${ }^{8-10}$ Supported by simulations, the material stack is chosen to provide an optimum field distribution within the device. The top electrode consists of an ultrathin metal multilayer, employing $1 \mathrm{~nm} \mathrm{Al}$ as surfactant for superior morphology. ${ }^{11}$ We further show that additional organic antireflection layers ${ }^{12,13}$ are, in particular, useful for semitransparent solar cells and greatly increase the transmittance if suitably designed. As characterization methods, currentvoltage measurements, external quantum efficiency (EQE), internal quantum efficiency (IQE), and the external reflection and transmission are used.

The solar cells are fabricated in a custom-made vacuum system (K.J. Lesker, UK) at a base pressure of $10^{-7} \mathrm{mbar}$

\footnotetext{
${ }^{a)}$ Electronic mail: jan.meiss@iapp.de.

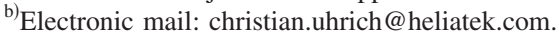

using shadow masks. Glass wafers coated with prestructured tin-doped indium oxide (ITO) (Thin Film Devices, USA) are used as substrates. The substrates are cleaned with organic solvents, followed by treatment in oxygen plasma. Thirtysix samples are made on the same substrate in one run. This ensures reproducible and comparable conditions for all layers and allows for an intentional variation in only single layers or parameters by partial shadow masking.

For good electron injection and hole blocking behavior, $10 \mathrm{~nm}$ of fullerene $\mathrm{C}_{60}$ doped with 4 wt $\%$ of the $n$-type dopant NDN1 (Novaled AG, Dresden, Germany; used for better processibility, comparable in performance to the commonly available 3,6-bis(dimethylamino) acridine [acridine orange base $\left.{ }^{14}\right]$ ) are deposited, followed by $15 \mathrm{~nm}$ of undoped electron transporter/light absorber $\mathrm{C}_{60}$. As main $\mathrm{ab}$ sorber layer, a BHJ of $35 \mathrm{~nm}$ zinc phthalocyanine $(\mathrm{ZnPc})$ and $\mathrm{C}_{60}$ (ratio 1:1) is used. $20 \mathrm{~nm}$ of $N, N^{\prime}$-diphenyl- $N, N^{\prime}$ bis(4' - $N, N$-bis(naphth-1-yl)-amino]-biphenyl-4-yl) benzidine (Di-NPB) doped with $10 \mathrm{wt} \%$ of the $p$-type dopant NDP9 (Novaled AG, Dresden, Germany) ${ }^{15}$ serves for hole extraction and transport. An additional layer of $1 \mathrm{~nm}$ NDP9 is used for improved charge carrier transport to the top electrode, which consists of $1 \mathrm{~nm} \mathrm{Al}$ and $14 \mathrm{~nm} \mathrm{Ag}$ to ensure a good compromise of transmission and conductivity. ${ }^{11} \mathrm{Fi}$ nally, an antireflection layer of $10 \mathrm{~nm}$ of $2 \mathrm{wt} \% n$-doped $\mathrm{C}_{60}$ is deposited onto some of the samples, in some cases, followed by $40 \mathrm{~nm}$ of tris-(8-hydroxy-quinolinato) aluminum $\left(\mathrm{Alq}_{3}\right)$. All organic materials except the dopants have been purified at least twice by vacuum gradient sublimation. Typical solar cell areas are around $6.32 \mathrm{~mm}^{2}$ (measured using a light microscope). The completed solar cells are encapsulated using glass encapsulation, sealed with a UV-hardened epoxy glue, in a nitrogen glovebox attached to the vacuum deposition chamber and then stored under ambient conditions. Current-voltage $J(V)$ characteristics are recorded using a source measurement unit (Keithley) under an AM 1.5G sun simulator (Steuernagel SC1200), monitored with a Hamamatsu S1337 silicon photodiode with respect to which intensities are given. The reported values are normalized to $100 \mathrm{~mA} / \mathrm{cm}^{2}$ and are not corrected for spectral mismatch. 
TABLE I. Solar cell characteristics.

\begin{tabular}{ccccccc}
\hline \hline & $\begin{array}{c}\mathrm{Alq}_{3} \\
(\mathrm{~nm})\end{array}$ & $\begin{array}{c}n-\mathrm{C}_{60} \\
(\mathrm{~nm})\end{array}$ & $\begin{array}{c}J_{\mathrm{SC}} \\
\left(\mathrm{mA} / \mathrm{cm}^{2}\right)\end{array}$ & $\begin{array}{c}V_{\mathrm{OC}} \\
(\mathrm{V})\end{array}$ & $\begin{array}{c}\mathrm{FF} \\
(\%)\end{array}$ & $\begin{array}{c}\eta \\
(\%)\end{array}$ \\
\hline $\mathrm{A}$ & 40 & 10 & 6.91 & 0.53 & 58.0 & 2.12 \\
$\mathrm{~B}$ & $\cdots$ & 10 & 7.25 & 0.54 & 58.2 & 2.29 \\
$\mathrm{C}$ & $\ldots$ & $\cdots$ & 7.35 & 0.53 & 57.3 & 2.23 \\
\hline \hline
\end{tabular}

The EQE is measured employing lock-in techniques (Signal Recovery SR 7265 lock-in amplifier) in a custommade setup with Xe illumination and a Newport Oriel Apex monochromator illuminator. For EQE measurements, the samples are measured under bias illumination through a photomask having an aperture of $2.958 \mathrm{~mm}^{2}$. Reflection $(R)$ and transmission $(T)$ measurements are performed using a UV3100/MPC-3100 spectrometer (Shimadzu). IQE is determined by dividing EQE by $(1-R-T)$.

For layer optimization, optical simulations are performed using a numerical code based on the transfer matrix approach. ${ }^{16}$ This technique uses refractive index $n$, extinction index $\kappa$ (obtained from reflection and transmission measurements ${ }^{17}$ ), and the layer thickness to calculate, e.g., photon absorption and distribution of the optical field within the solar cell. ${ }^{17-19}$

The solar cells presented in this letter contain identical material stacks, except that there is either a combination of $10 \mathrm{~nm} n$-doped $\mathrm{C}_{60}$, followed by $40 \mathrm{~nm} \mathrm{Alq}_{3}(\mathrm{~A})$ evaporated onto the top contact, or a capping layer of $10 \mathrm{~nm} n$-doped $\mathrm{C}_{60}(\mathrm{~B})$, or no capping layer [denoted as (C)]. Examples of the OSC characteristics obtained for different capping layer thicknesses are summarized in Table I, with the $J(V)$ graphs with and without illumination shown in Fig. 1.

All solar cells exhibit open circuit voltages $V_{\mathrm{OC}}$ $\approx 0.53 \mathrm{~V}$, which is typical for $\mathrm{ZnPc}: \mathrm{C}_{60}$ heterojunctions. High fill factors FF of $>57 \%$ hint at low recombination and only small leakage currents. As seen in Fig. 1, all samples exhibit a good rectifying behavior, suggesting high parallel resistances. FF and the slope in the forward direction are attributed to low series resistance $R_{\mathrm{S}}$. Both high $V_{\mathrm{OC}}$ and FF are attributed to excellent electrical contact due to the doped transport layers: hole extraction is provided by $p$-DiNPB,

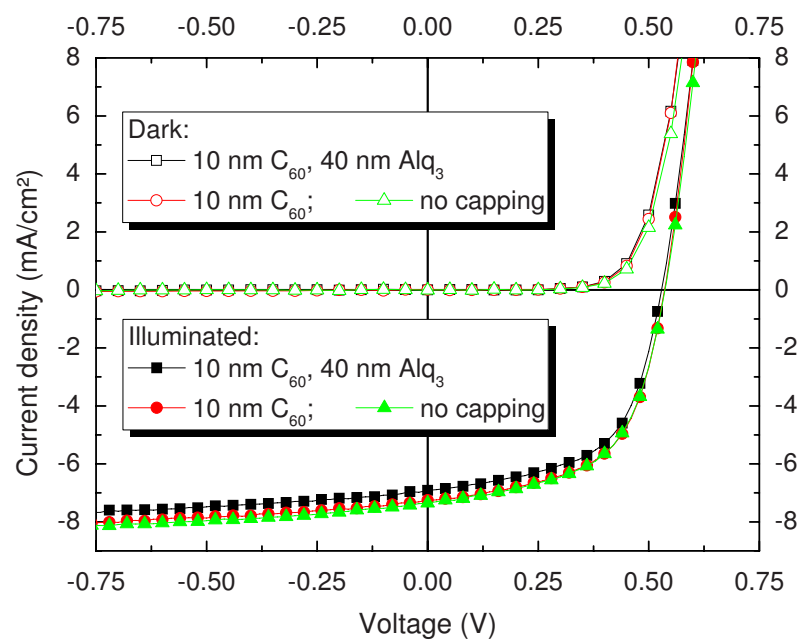

FIG. 1. (Color online) Current-voltage characteristics of semitransparent OSCs with different capping layers, normalized to $100 \mathrm{~mA} / \mathrm{cm}^{2}$ (full symbols) or in the dark (empty symbols). Triangles: no capping; circles: $10 \mathrm{~nm}$ $n$ - $\mathrm{C}_{60}$; and squares: $10 \mathrm{~nm} n-\mathrm{C}_{60}$ and $40 \mathrm{~nm} \mathrm{Alq}$.

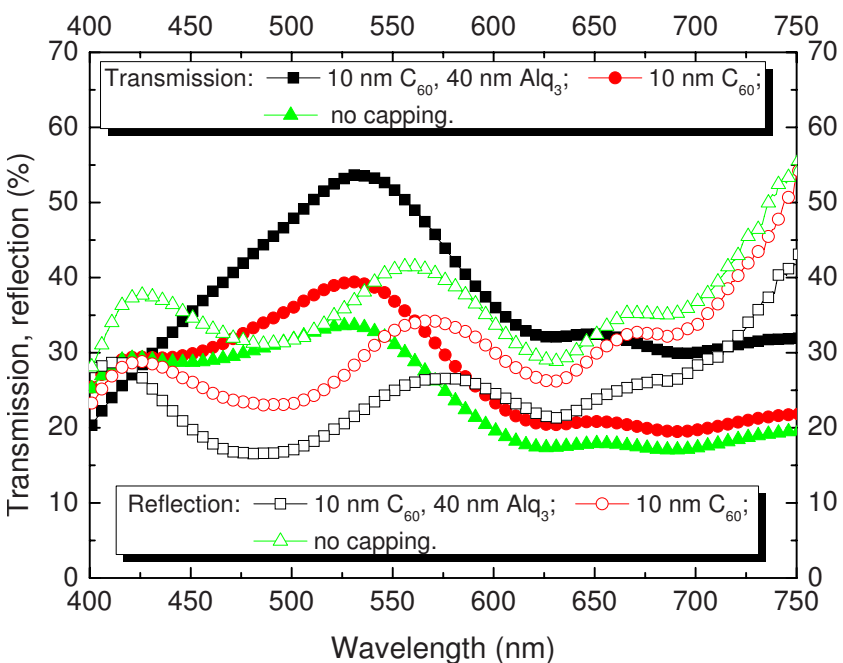

FIG. 2. (Color online) Transmission (filled symbols) and reflection (empty symbols) of semitransparent organic solar cells with different capping layers. Triangles: no capping; circles: $10 \mathrm{~nm} n-\mathrm{C}_{60}$; and squares: $10 \mathrm{~nm} \mathrm{n}$ - $\mathrm{C}_{60}$ and $40 \mathrm{~nm} \mathrm{Alq}$

while the $n-\mathrm{C}_{60}$ leads to efficient electron transport. Hence, the two transport layers act as semipermeable membranes that prevent exciton quenching at the electrodes. ${ }^{8,9}$

In the present work, BHJs are used to obtain high photocurrents. ${ }^{7}$ For the three samples, clear differences in the short circuit current densities $J_{\mathrm{SC}}$ are observed: sample A exhibits $J_{\mathrm{SC}}=6.91 \mathrm{~mA} / \mathrm{cm}^{2}$, leading to an efficiency of $\eta$ $=2.12 \%$. If only $10 \mathrm{~nm} n-\mathrm{C}_{60}$ are present (no $\mathrm{Alq}_{3}$, sample B), the current increases to $7.25 \mathrm{~mA} / \mathrm{cm}^{2}$, raising $\eta$ to 2.29\%. A further increase in $J_{\mathrm{SC}}$ to $7.35 \mathrm{~mA} / \mathrm{cm}^{2}(\eta$ $=2.23 \%$ ) is observed when no capping layer is present (sample C). These changes in photocurrent and efficiency are attributed to the optical properties of the OSC stacks, which are modified by the capping layer.

To understand this phenomenon, three effects have to be considered: firstly, the capping layer acts as dielectric antireflection coating, modifying the interface between metal top contact $(\mathrm{Al} / \mathrm{Ag})$ and ambient air. This leads to an increased light transmission through the metal contact into, or out of, the solar cell. ${ }^{13}$ Secondly, the external capping layers are used to influence the optical field amplitude within the solar cell stack itself, especially by controlling the field in the light absorption layers $\left(\mathrm{ZnPc}: \mathrm{C}_{60}\right.$ and intrinsic $\left.\mathrm{C}_{60}\right)$. The third effect is parasitic absorption of the capping layer itself. At wavelengths of around $400-550 \mathrm{~nm}$, considerable absorption is to be expected since the $n-\mathrm{C}_{60}$ absorbs in this part of the spectrum. Only at higher wavelengths, the absorption of $\mathrm{ZnPc}$ becomes the predominant feature of the OSC and the relative contribution of $\mathrm{C}_{60}$ is expected to be negligible (e.g., in the $600-700 \mathrm{~nm}$ range).

The experimental data demonstrate the rather subtle interplay of the various effects: measurements of transmission and reflection for all devices are shown in Fig. 2, with the corresponding EQE and IQE displayed in Fig. 3. The OSC without any capping layer exhibits a transmission of $T$ $\approx 30 \%$ in the wavelength range of $400-550 \mathrm{~nm}$, which then drops to below $20 \%$ in the $600-750 \mathrm{~nm}$ range, the wavelength range in which $\mathrm{ZnPc}$ absorbs. Upon the addition of a capping layer, it is notable that the reflection of device B is lowered in most of the visible spectrum, increasing the overall transmission. Within experimental error, the transmission 


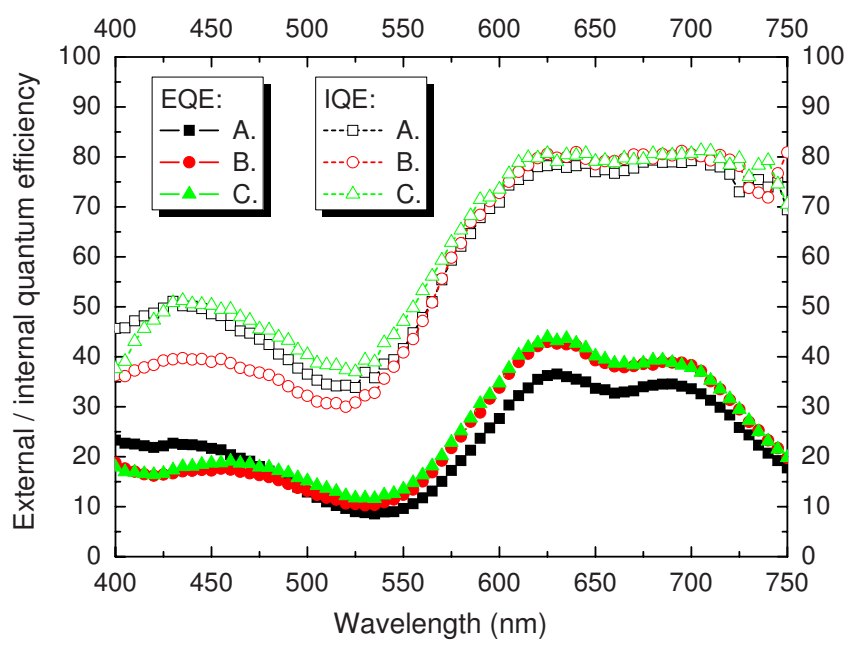

FIG. 3. (Color online) EQE (filled symbols) and IQE (empty symbols) of semitransparent OSCs with different capping layers. Squares: (A) $40 \mathrm{~nm}$ $\mathrm{Alq}_{3} / 10 \mathrm{~nm} n-\mathrm{C}_{60}$; circles: (B) $10 \mathrm{~nm} n$ - $\mathrm{C}_{60}$; and triangles: (C) no capping.

is not affected in the range of $400-450 \mathrm{~nm}$ due to the parasitic absorption of the $\mathrm{C}_{60}$ capping layer. For the additional $40 \mathrm{~nm} \mathrm{Alq}$ introduced in sample A, the reflection is further decreased and transmission increased. The only exception is seen at $\lambda<450 \mathrm{~nm}$, where interference effects within the solar cell stack lead to increased absorption in the $\mathrm{C}_{60}$ absorber/ electron transporter layers next to the $\mathrm{ZnPc}: \mathrm{C}_{60}$ blend.

This is supported by the EQE and IQE data in Fig. 3: devices $\mathrm{B}$ (10 $\mathrm{nm} \mathrm{C}_{60}$ capping) and $\mathrm{C}$ (no capping) have similar $\mathrm{EQE}$ and $\mathrm{IQE}$, with $\mathrm{EQE}$ of $\mathrm{C}$ being just slightly larger (corresponding to the photocurrent). However, the IQE exhibit differences at $\lambda<550 \mathrm{~nm}$. This is attributed to parasitic absorption in the capping, which does not contribute to the photocurrent due to quenching of the photogenerated excitons at the semitransparent metal top electrode. Device A further modifies the photon flux within the absorber stack, shifting the field density away from the blend layer toward the $\mathrm{C}_{60}$ layer within the device. This leads to the overall lower absorption in the $\mathrm{ZnPc}$ range, increases harvesting in the $\mathrm{C}_{60}$ absorber layer next to the blend, and at the same time decreases parasitic absorption in the $\mathrm{C}_{60}$ capping layer. Correspondingly, EQE is increased at $\lambda<450 \mathrm{~nm}$, with IQE being similar to device $\mathrm{C}$ (no capping) with only minor losses to parasitic absorption.

The lower absorption, caused by a weaker field intensity in the $\mathrm{ZnPc}: \mathrm{C}_{60}$ blend, leads to lower photocurrents $J_{\mathrm{SC}}$ in the presence of multilayer capping. As a consequence, this also lowers the power conversion efficiency of devices A and B. Nonetheless, the relative loss in photocurrent introduced by the capping $(\approx 5 \%)$ is very small compared to the relative increase in transmission (depending on the wavelength up to $85 \%$ relative increase), which makes capping layers a useful concept in semitransparent solar cells for window applications. An example of a photograph of the IAPP logo seen through the photoactive layer of a semitransparent OSC is seen in Fig. 4 to illustrate the transparency achieved in a sample containing $\mathrm{Alq}_{3}$ and $\mathrm{C}_{60}$. The photograph shows four OSC having $\approx 6.32 \mathrm{~mm}^{2}$ each in the middle, two of which are marked with rectangles.

In summary, we present semitransparent organic solar cells with much higher efficiency than previously reported. The devices use the $p-i-n$ architecture and ultrathin metal
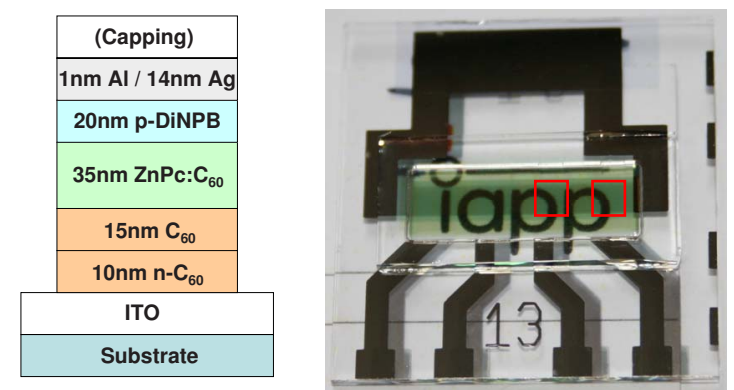

FIG. 4. (Color online) Left: solar cell stack. Right: photograph of the IAPP Logo, seen through semitransparent OSC. The photograph shows four solar cells having $\approx 6.32 \mathrm{~mm}^{2}$ each in the middle, two of which are marked with rectangles. The metal films (dark) are electrode reinforcements, but do not reach the active areas in the middle.

layers as semitransparent top electrode. The effects of different capping layers $\left(\mathrm{C}_{60}\right.$ and $\left.\mathrm{Alq}_{3}\right)$ are discussed using current-voltage, EQE, IQE, and optical measurements. It is shown that a capping layer increases the transmission significantly to over $50 \%$, but leads to slightly lower photocurrents $(\approx 5 \%)$ due to wavelength-specific parasitic absorption and modification of the optical field within the device. The OSC exhibits power conversion efficiencies of $2.1 \%-2.2 \%$ with transmissions exceeding $30 \%-50 \%$ in the visible part of the spectrum.

This work was funded by the Bundesministerium für Bildung und Forschung in the framework of the InnoProfile project Grant No. (03IP602).

${ }^{1}$ C. W. Tang, Appl. Phys. Lett. 48, 183 (1986).

${ }^{2} 2 \mathrm{~cm}^{2}$ small-molecule organic solar cell, made by Heliatek/IAPP, measured by ISE (Freiburg, Germany) in 2009 as having $6.07 \%$ under standard reporting conditions.

${ }^{3}$ R. Timmreck, J. Meiss, A. Merten, R. Schueppel, M. Furno, C. Uhrich, W.-M. Gnehr, M. Pfeiffer, M. K. Riede, and K. Leo, Proceedings of the 24th EUPVSEC, Hamburg, Germany, 2009 (unpublished).

${ }^{4} 0.047 \mathrm{~cm}^{2}$ polymer organic solar cell, made by Solarmer, measured by NREL in 2009 as having $6.77 \%$ under standard reporting conditions.

${ }^{5}$ R. Bailey-Salzman, B. P. Rand, and S. R. Forrest, Appl. Phys. Lett. 88, 233502 (2006).

${ }^{6}$ R. Koeppe, D. Hoeglinger, P. A. Troshin, R. N. Lyubovskaya, V. F. Razumov, and N. S. Sariciftci, ChemSusChem 2, 309 (2009).

${ }^{7}$ M. Hiramoto, H. Fujiwara, and M. Yokoyama, J. Appl. Phys. 72, 3781 (1992).

${ }^{8}$ B. Maennig, D. Gebeyehu, P. Simon, F. Kozlowski, A. G. Werner, F. Li, S. Grundmann, S. Sonntag, M. Koch, K. Leo, M. Pfeiffer, H. Hoppe, D. Meissner, N. S. Sariciftci, I. Riedel, V. Dyakonov, J. Parisi, and J. Drechsel, Appl. Phys. A: Mater. Sci. Process. 79, 1 (2004).

${ }^{9}$ K. Walzer, B. Maennig, M. Pfeiffer, and K. Leo, Chem. Rev. (Washington, D.C.) 107, 1233 (2007).

${ }^{10}$ J. Drechsel, B. Maennig, F. Kozlowski, M. Pfeiffer, K. Leo, and H. Hoppe, Appl. Phys. Lett. 86, 244102 (2005).

${ }^{11}$ J. Meiss, M. K. Riede, and K. Leo, J. Appl. Phys. 105, 063108 (2009).

${ }^{12}$ B. O'Connor, K. H. An, K. P. Pipe, Y. Zhao, and M. Shtein, Appl. Phys. Lett. 89, 233502 (2006).

${ }^{13}$ J. Meiss, N. Allinger, M. K. Riede, and K. Leo, Appl. Phys. Lett. 93, 103311 (2009).

${ }^{14}$ F. Li, M. Pfeiffer, A. Werner, K. Harada, K. Leo, N. Hayashi, K. Seki, X. Liu, and X.-D. Dang, J. Appl. Phys. 100, 023716 (2006).

${ }^{15}$ Used for better processibility, comparable in performance to the commonly available 2,3,5,6-tetrafluoro-7,7,8,8-tetracyanoquinodimethane (F4TCNQ).

${ }^{16}$ W.-M. Gnehr, unpublished.

${ }^{17}$ T. Fritz, J. Hahn, and H. Boettcher, Thin Solid Films 170, 249 (1989).

${ }^{18}$ J. Meiss, N. Allinger, C. Falkenberg, K. Leo, and M. K. Riede, Proc. SPIE 7416, 741603 (2009).

${ }^{19}$ R. Schueppel, R. Timmreck, N. Allinger, T. Mueller, M. Furno, C. Uhrich, K. Leo, and M. Riede, J. Appl. Phys. (submitted). 